\title{
Error Analysis - Types and Causes of Errors in English Writing among Chinese Students
}

\author{
Zhuoyang Li* \\ Shaanxi Xueqian Normal University, Xi'an 710100, Shaanxi Province, China \\ *Corresponding author: Zhuoyang Li, 18004092820@163.com
}

\begin{abstract}
This article analyzes errors with regard to the types and causes of errors commonly committed by Chinese EFL (English as a foreign language) learners. It covers the concepts and theories concerning error analysis, synthesizes previous research, as well as identifies the flaws and gaps found in those literatures. This article provides several teaching suggestions based on previous analyses, which have found that the misuse of verbs and articles are the most common errors in English writing among Chinese students. Based on this, most studies attributed those errors to the negative transfer of Chinese due to the thought patterns and disparities between Chinese and English.
\end{abstract}

Keywords: Error analysis; English writing; EFL

Publication date: August 2021; Online publication: August 30, 2021

\section{Introduction}

Error analysis has become one of the important learning and teaching process in EFL learning for decades. In the 1960s, error analysis (EA), which studies the types and causes of language errors, was developed as an alternative to contrastive analysis in applied linguistics. Even though it was criticized and replaced by the interlanguage theory after some time ${ }^{[1]}$, EA is still useful in learning and teaching English.

Errors are unavoidable constitutes in language learning, so it is important to understand what constitutes an error. For decades, there have been various explanations for the causes of errors; both external factors and internal factors. The errors in English writing among Chinese students have their own features. It is of great importance to research, specifically on this issue, to discover the types of errors and to explore the causes in detail.

This article, based on Chinese EFL learners, synthesizes and analyzes the various types of errors and core causes for those errors. It mainly focuses on psychological areas, which provides methodology for both learners and teachers. Through summarizing the research findings on the error analysis in English writing among Chinese EFL learners, this article provides a comprehensive and overall picture of errors commonly found in English writing in order to raise awareness of potentials errors among teachers and students. Finally, this article also provides constructive suggestions based on the analysis of the causes of those errors. This research would probably help Chinese teachers and students to be aware of the potential errors in English writing as well as to correct and avoid errors as much as possible.

\section{Literature review}

\subsection{Types of errors}

Error analysis has been studied and discussed for decades. Subsequently, different error classification systems were proposed by various linguists. Duan had analyzed the misuse of tense in English writing 
among Chinese college students. In total, nine types of misuse were identified through a corpus-based research $^{[2]}$. After some time, Zheng, Park, and Zhan stated through their research findings that the misuse of tense and verb forms are the most common errors in English writing among Chinese students ${ }^{[3,4]}$. Besides this, errors such as run-on sentences, omission of articles, and plural suffix -s, frequently appeared in Chinese students' English writing. Xia proposed that the infinitive errors made by Chinese students are the majority errors and found that infinitive and gerund phrases are one of the most difficult aspects to learn and use among Chinese learners ${ }^{[5]}$. Sun summarized that the negative transfer of Chinese sentence patterns leads up to syntactic errors in English writing, including topic-comment sentences, multi-predicate sentences, and paratactic sentences ${ }^{[6]}$. Based on this, three typical Chinese thoughts were proposed: Chinese global thought, Chinese imaginational thought, and Chinese dialectical thought result in subjectless sentences, multi-verbs sentences, and fragments, respectively.

\subsection{Causes of errors}

There are various causes of errors committed by Chinese students in their English writing. Many studies consistently focus on the negative transfer of Chinese in English writing. Negative transfer could come from Chinese thinking patterns or conceptual absence. Anderson proposed the ACT (adaptive control of thought) model, which contributes to the understanding of human cognition concerning memory, inferential reasoning, language processing, and language acquisition ${ }^{[7]}$. He made a clear distinction between declarative knowledge and procedural knowledge. In the learning of L2 (second language), L1 knowledge often acts as a procedural constraint, and this helps the learners to achieve an acceptable L2 fluency or fills a perceived or unperceived L2 knowledge gap. Kellerman proposed the notion of psychotopology, which refers to the distance between two languages as perceived by the learner ${ }^{[8]}$. The psychological structure of the learners' L1, their perception of the L1 target language distance, and their actual knowledge of the target language, all control their use of transfer.

Many previous studies indicated that transfer errors are the main reason leading to errors committed by Chinese EFL learner in English. Ni proposed that the main cause accounting for the errors is the thought pattern ${ }^{[9]}$. Language influences the way people perceive, organize, and communicate; thus, the transfer of linguistic knowledge negatively affects the thought patterns in deep cognitive process. Duan had analyzed that the main cause of errors for the misuse of tense in English writing is the negative transfer of Chinese ${ }^{[2]}$. Since there is no concept of tense in Chinese, Chinese students tend to pay more attention to generating ideas in writing Chinese compositions. In English writing, however, writing habits naturally affect the use of English. Xia proposed that the infinitive errors made by Chinese students in English writing are attributed to the overgeneralization of rules of the target language. Zhu analyzed the syntactic transfer from Chinese to English based on students with different proficiency. The results showed that the extent of syntactic transfer is large for complicated target structures and among learners with a lower proficiency level, although higher proficiency level learners may also rely on the syntactic structure of their L1, which is Chinese ${ }^{[10]}$.

Zheng and Park claimed that the errors may be caused by the influence of L1 or by leaners' selfconstruction. They concluded that some types of overgeneralizations could indicate that learners are actively building their own cognitive grammatical understanding ${ }^{[3]}$. In addition to that, Sun had analyzed some ungrammatical patterns in the free writing among Chinese EFL learners, in which it was found that the misuse of determiners is the most frequent grammatical error in Chinese students' writing and is attributed to inappropriate L1 transfer. It was also mentioned that the explicit instruction on these frequent ungrammatical patterns is necessary and helpful ${ }^{[11]}$. Zhan summarized that the ultimate cause of errors is 
due to the learners' linguistic ignorance of the TL (target language), and secondly misapplying avoidance ${ }^{[4]}$. Errors made by learners are related to their cognitive process. Patrick, Yang, and Sui also discussed in their paper that errors in written essays are mainly due to the interference of one's own mother tongue and the overgeneralization of ideas, especially in terms of verb tense and preposition. They also discovered that quite a number of errors are due to carelessness ${ }^{[12]}$.

\section{Argument}

The studies concerning different types of errors commonly committed by Chinese students in English writing vary in results. There were different results in regard to the most frequent errors or common errors, such as articles or verb tenses. However, they failed to provide a clear classification of error types along with limited collected data. Th research results within a small number of participants may not be representative. Hence, the research results can only be a form of reference to some extent.

In regard to the causes of errors, these studies either overemphasized the importance of students' cognitive process and looked down upon the language input, or vice versa. These studies failed to provide a systematic analysis on the negative transfer of Chinese in English writing. Furthermore, the data is considerably limited in written English with minimal attention to oral data. Therefore, the analysis of causes of errors are not comprehensive enough to include both written and oral data. It is critically essential to conduct a long-term study on English writing in China involving more participants. The majority of these studies have given a detailed analysis of errors but without providing any plausible solutions to these problems.

\section{Implications for pedagogy}

Error analysis is concerned with a rich and complex psycholinguistic view of the learner, but its sophisticated use is still in its infancy ${ }^{[13]}$. There is a need to explore the learners' psychological process in language learning so that the understanding of learner' errors can be enhanced. Error correction is fundamentally a cognitive process; thus, errors cannot be eliminated until they have a clear awareness of them.

First, both teachers and students need to pay more attention to those frequent errors. Second, explicit instruction is necessary and helpful for EFL learners in raising their awareness of target language structures because of their lack of L2 knowledge and the absence of some grammatical forms in L1, such as articles and inflections. Teachers could also give a hand in students' limited learning ability so as to improve EFL learners' accuracy and fluency more effectively in English writing. Third, increasing the comparison between Chinese and English in the aspects of thought and grammatical systems could help to fill the gap between Chinese and English.

\section{Conclusion}

This article incorporates several recent studies, which analyzed the errors committed by Chinese students in their English writing. With regard to the types of errors, results from those studies showed that the misuse of tense and articles are the most common errors. The causes of errors are primarily due to the negative transfer of Chinese. The thought patterns, lack of knowledge, and different proficiency are factors affecting the English writing among Chinese students. This article provides a panoramic view of errors in English writing among Chinese students, from which both teachers and students are able to recognize the overall potential errors in English writing. In addition, based on the analysis of the causes, more attention should be paid to them. 


\section{Disclosure statement}

The author declares that there is no conflict of interest.

\section{References}

[1] Selinker L, 1972, Interlanguage. International Review of Applied Linguistics, (10): 201-31.

[2] Duan M, 2011, A Corpus-Based Study of the Misuse of Tenses in the English Composition of Chinese College Students. English Language Teaching, 4(4): 173-80.

[3] Zheng C, Park T, 2013, An Analysis of Errors in English Writing Made by Chinese and Korean University Students. Theory and Practice in Language Studies, 3(8): 1342-51.

[4] Zhan H, 2015, Frequent Errors in Chinese EFL Learners' Topic-Based Writings. English Language Teaching, 8(5): 72-81.

[5] Xia L, 2012, A Corpus-Based Study of the Infinitive Errors Made by Chinese College Students. English Language Teaching, 5(6): 154-7.

[6] Sun F, 2013, Negative Transfer of Chinese Sentence Patterns on Students' English Writing. Journal of Language Teaching and Research, 4(6): 1298.

[7] Anderson R, 1979, The Relationship between First Language Transfer and Second Language Overgeneralization, in The Acquisition and Use of Spanish and English as First and Second Languages, Anderson R, TESOL, Washington, D.C.

[8] Kellerman E, 1977, Towards a Characterization of the Strategies of Transfer in Second Language Learning. Interlanguage Studies Bulletin, 2: 58-145.

[9] Ni H, 2013, An Empirical Research on Negative Transfer in College Non-English Majors' ChineseEnglish Sentence Translation. Theory and Practice in Language Studies, 3(6): 995-1004.

[10] Zhu L, 2014, A Study of Syntactic Transfer in Relative Clause Learning of Chinese College English Majors. Theory and Practice in Language Studies, 4(3): 613-7.

[11] Sun X, 2014, Ungrammatical Patterns in Chinese EFL Learners' Free Writing. English Language Teaching, 7(3): 176-83.

[12] Patrick JM, Yang Z, Sui M, 2014, Error analysis in English Written Essays of Undergraduate Students of Northeast Normal University Changchun. Language in India, 14(5): 123.

[13] Jiang X, Xie F, 2007, Error Analysis and the EFL Classroom Teaching. US-China Education Review, 4(9): 10-4. 